\section{Response-term predictability and stimulus-response conceptual similarity in paired-associates learning*}

\author{
J. D. READ, University of Lethbridge, Lethbridge, Alta., Canada \\ and \\ SAM C. BROWN, Kansas State University, Manhattan, Kans. 66506
}

Paired-associates learning was significantly facilitated when lists were constructed such that, given the $S$ term, the conceptual category of the $R$ term was highly predictable. Increased predictability served to minimize the effects of S-R conceptual similarity and, it was concluded, to facilitate PA learning by restricting the number of possible response alternatives.

The organizational bases of the storage and retrieval of information in memory have recently taken on much importance in verbal learning, and particularly paired-associates learning. For example, investigators have used a variety of techniques from the standard paired-associates task to a "free-pairing" procedure (Brown \& Read, 1970) in order to gain information about the possible organizational strategies employed by $S$ while learning a set of verbal items. In paired-associates learning, the effects of formal, conceptual, and meaningful similarity have been well researched and, in general, it has been found that the higher the level of similarity, the slower the learning (e.g., Underwood, Ekstrand, \& Keppel, 1965). Whereas the majority of the investigations have been confined to manipulations of similarity among stimulus or response terms, Thompson $\&$ Fritzler (1968) have shown that high formal similarity between the stimulus and response terms may facilitate learning if such similarity is located within rather than between pairs. Moreover, the effect of similarity was modified by the degree of list organization, i.e., the predictability of the position of a repeated letter in the stimulus and response terms. That is, depending upon the list structure, some component of a response term was highly predictable for $\mathrm{S}$ on the basis of the stimulus-term spelling alone. As yet, the effects of such list organization on paired-associates learning has not been extended to either conceptual or meaningful similarity. However, as part of a study concerned with a comparison between massed and distributed practice, Underwood \& Schulz (1961) constructed two 16-pair lists of low

*This research was supported by Public Health Serrice Research Grant MH-11179. stimulus-response conceptual similarity which varied in terms of response-term predictability. The sets of stimulus and response terms each contained four different conceptual categories, each represented by four category members. Two levels of predictability were constructed by pairing either four conceptually dissimilar or conceptually similar response terms with the four members of a stimulus-term conceptual category. In other words, for the two groups of Ss, respectively, the conceptual category of a particular response term given the stimulus term was either unpredictable or highly predictable. Although greater numbers of overt errors were obstived in the high than in the low predictability list, difference in overall performance between the two levels of predictability. In summary, the effects of predictability as an organizational variable in paired-associates learning do not seem to be well understood and seem to be in need of further investigation.

The results of the available studies suggest, albeit one involving formal, the other conceptual similarity, that high predictability will facilitate paired-associates learning most under conditions of heavy interference, i.e., when similarity between stimuli and responses is high. The present study was designed to examine this possibility explicitly in the instance where conceptual similarity would be expected to be a weak or a strong source of interference, and at the same time the basis for either low or high predictability.

\section{SUBJECTS}

The 176 Ss were students enrolled in an introductory psychology course at Kansas State University, and they completed the experiment for extra class credit. All Ss were assigned to the experimental groups in order of appearance at the laboratory. the results did not reveal a significant
DESIGN AND MATERIALS

Two basic lists were used, each consisting of 25 paired associates. The 25 stimulus terms were identical for both lists and were divided into five subsets, each subset representing five instances of a different conceptual category (i.e., countries, vegetables, trees, animals, and sports). For one list, low (L) conceptual similarity existed between stimulus and response terms. That is, response terms were from the following five different categories: tools, school subjects, cars, instruments, and clothes. In the second list, high $(\mathrm{H})$ similarity was represented by complete overlap between stimulus- and response-term categories. That is, the five response-term categories were also countries, vegetables, trees, animals, and sports

The predictability variable was manipulated by pairing the stimulus and response terms of each list in two different ways. For one-half of the Ss learning each list, the five members of each stimulus-term subset were paired with response terms, each representing a different conceptual category. Thus, given the stimulus term, the predictability of the response-term category was low. For the remaining one-half of the Ss, the five members of each stimulus-term subset were paired with five response terms, also of a common conceptual category, e.g., trees with tools in the low similarity list or trees with trees in the high similarity list. Thus, for these Ss, the predictability of the response-term category was high. The four experimental conditions were denoted, respectively, in terms of similarity (S) and predictability (P) as LS-LP, LS-HP, HS-LP, and HS-HP.

\section{PROCEDURE}

Learning was carried out by the recall method of paired-associates learning for 12 trials. The pairs were projected individually on a screen by a Kodak Carousel projector at a $2 \cdot \mathrm{sec}$ rate. During test series, stimulus terms were presented alone, each for $4 \mathrm{sec}$. Intra- and intertrial intervals were $6 \mathrm{sec}$ in duration. The Ss, who completed the experiment in groups of 22 , were instructed to write down in preassembled booklets the correct response term for each stimulus term on test trials. A total of 44 Ss served in each experimental condition.

$$
\text { RESULTS }
$$

For each $S$, the number of errors within 12 test trials was tabulated, and the mean total errors for all conditions are presented in Table 1. In agreement with the results found for both formal and meaningful similarity (e.g., Umemoto, 1962; Umemoto \& Hilgard, 1961), low similarity conditions $(\overline{\mathrm{X}}=$ 62.3 ) were significantly superior to 
Table 1

Meams and Siandand Debrations (in Parenthesest for Total, Overt, and Percentage Osert Frrors in Fach Condition

\begin{tabular}{|c|c|c|c|c|c|}
\hline \multirow[b]{2}{*}{ Condition } & \multirow[b]{2}{*}{$\begin{array}{l}\text { Total } \\
\text { Errors }\end{array}$} & \multicolumn{2}{|c|}{ Osert Errors } & \multicolumn{2}{|c|}{ Pereentage } \\
\hline & & $\begin{array}{l}\text { Stimulus } \\
\text { Term }\end{array}$ & $\begin{array}{c}\text { Response } \\
\text { Term }\end{array}$ & Within & Between \\
\hline$L S-1, P$ & $\begin{array}{c}68.84 \\
(33.17)\end{array}$ & $\begin{array}{c}1.9 .3 \\
(2.84)\end{array}$ & $\begin{array}{l}10.61 \\
(6.96)\end{array}$ & $\begin{array}{c}5.71 \\
(5.41)\end{array}$ & $\begin{array}{l}14.25 \\
(9.55)\end{array}$ \\
\hline LS.HP & $\begin{array}{c}55.80 \\
(23.38)\end{array}$ & $\begin{array}{c}0.75 \\
(1.26)\end{array}$ & $\begin{array}{c}13.89 \\
(12.18)\end{array}$ & $\begin{array}{c}17.45 \\
(12.72)\end{array}$ & $\begin{array}{c}7.35 \\
(5.51)\end{array}$ \\
\hline IIS-LP & $\begin{array}{l}103.27 \\
(57.84)\end{array}$ & $\begin{array}{c}10.80 \\
(14.34)\end{array}$ & $\begin{array}{c}17.11 \\
(17.02)\end{array}$ & $\begin{array}{c}7.14 \\
(6.70)\end{array}$ & $\begin{array}{c}16.47 \\
(10.58)\end{array}$ \\
\hline IIS-IIP & $\begin{array}{c}50.84 \\
(21.12)\end{array}$ & $\begin{array}{c}9.05 \\
(9.18)\end{array}$ & $\begin{array}{l}15.25 \\
(9.18)\end{array}$ & $\begin{array}{c}44.78 \\
(20.84)\end{array}$ & $\begin{array}{c}2.32 \\
(5.91)\end{array}$ \\
\hline
\end{tabular}

high similarity conditions $(\bar{X}=77.1)$ $[F(1,172)=6.87, p<.01]$. Moreover, performance was significantly better under high $(\overline{\mathrm{X}}=53.3$ ) than under low predictability conditions $(\overline{\mathrm{X}}=86.1)$ $[F(1,172)=33.90, p<.001]$. That the effects of predictability were differential to the level of similarity is indicated by a significant Similarity by Predictability interaction $[F(1,172)=$ $12.27, p<.0011$. In agreement with the results of earlier research (Underwood \& Schulz, 1961), the reduction in errors from low to high predictability for low similarity Ss failed to reach significance $(p>.05)$. On the other hand, the reduction in errors from low to high predictability for high similarity Ss clearly accounted for the significant main effect of predictability. This reduction, in fact, served io eliminate the difference between low and high similarity for high predictability Ss.

In an attempt to understand the overall performance differences obtained with total errors, the number of stimulus-term (stimuli given as responses) and response-term (misplaced but otherwise correct responses) overt errors were tabulated. The mean numbers of these errors committed in each condition are presented in Table 1 . In separate analyses of the overt error data, the superiority of low similarity $(\overline{\mathrm{X}}=1.34$ and 12.25 , respectively) over high similarity $(\overline{\mathrm{X}}=9.93$ and 16.18) conditions proved to be statistically significant in both cases $[F s(1,172) \geqslant$ $4.67, \mathbf{p}<.051$. However, neither the main effects of predictability nor the Similarity by Predictability interactions reached significance $\left(F_{\mathbf{s}} \leqslant 2.14, p>.05\right)$. In short, the numbers of overt errors reflect the overall performance difference between the two levels of similarity but not the difference between the two levels of predictability.

In order to obtain a reflection of the effect of predictability in the types of errors committed, the total number of overt errors was divided into two classes. That is, an incorrectly placed increase in the number of within-concept substitutions

DISCLSSION

It is apparent from the results that the similarity variable exerted a large effect upon paired-associates performance. The significantly greater numbers of stimulus-term and response-term overt errors committed in the high than in the low similarity conditions reflect, respectively, greater stimulus-response interference and considerably more awareness of the potentially correct response-term categories for high than for low similarity Ss. With respect to the low similarity conditions alone, the present results are in agreement with those of Underwood \& Schulz (1961). That is, the manipulation of predictability did not produce an overall performance difference. On the other hand, the predictability variable was clearly effective for high similarity conditions.

Recently, Bower \& Bolton (1969) have shown in a paired-associates learning situation that when a consistent relational rule (e.g. rhyming) exists between stimulus and response terms and when $\mathrm{S}$ is aware of this rule, performance is vastly improved as compared to lists in which such a rule is not present. These authors argued that S's application of the rule improves performance by restricting the number of possible response alternatives. In the present investigation, the applicable rules for high predictability Ss might be verbalized by $S$ as "the members of one category with members of the same category [Condition HS-HP] or another category [Condition LS-HP]." Measures of the extent of such a response category restriction would be the numbers of between-concept and within-concept substitutions. For both low and high similarity conditions, there were significant reductions in the former and significant increases in the latter category as predictability increased from low to high. Viewed in this light, increasing response-term predictability serves to restrict the number of response alternatives. Since this restriction, theoretically, should be equivalent for both low and high similarity conditions, it would seem likely that the relational rule was more obvious for high than for low similarity Ss. Assuming that $S s$ in C $\circ n d i t i o n$ L S H P a n d Condition HS-HP became aware of the existence of certain rules within the list simultaneously, Ss in Condition LS-HP were then, in addition, required to learn the appropriate stimulus-response category contingencies (e.g., trees with tools, sports with cars, etc.). The Ss in Condition HS-HP, however, had this information immediately available 
(e.g., irees with trees, sports with sports, etc.). It would follow then that low similarity $S$ might have profited more from an increase in predictability if some preexperimental training had involved the acquisition of the appropriate stimulus-response categorical associations.

The above interpretation of the effects of predictability clearly emphasizes organization in the $S$ rather than organization in the list. That is, the distribution of within and between errors obtained in the study may also be explained on the basis of stimulus and response generalization. For example, the high percentage of within errors in Condition HS-HP may reflect high degrees of intra- and interpair interference or S's guessing strategy. Although the latter interpretation is favored, the data do not allow a clear difierentiation between the two alternatives. In summary, the present experiment points to the importance of response-term predictability as an organizational variable in paired-associates learning. It was concluded that such predictability served to restrict the number of response alternatives and, as a result, to mitigate the effects of stimulus-response conceptual similarity.

\section{REFERENCES}

BOWER, G. H., \& BOLTON, L. S. Why are rhymes easy to learn? Journal of Experimental Psychology, 1969, 82, 453-461

BROWN, S. C., \& READ, J. D. Associative organization in paired-associate learning and transfer. Journal of Verbal Learning
\& Verbal Behatior, 1970,9.317-326.

THOMPSON, C. P.. \& FRITZLER, D. E. Paired-associate acquisition: Some effects of inter- and intrapair similarity. Journal of Experimental Psychology, 1968,78, 107-112.

UMEMOTO. T Paired-associate learning as a function of similarity: Semantic similarity between stimulus- and response-items. American Joumal of Psychology. 1962, 75, 85-93.

UMEMOTO T. \& HILGARD, E. R. Paired-associate learning as a function of similarity: Common stimulus and response items within the list. Journal of Experimental Psychology, 1961, 62. 97-104.

UNDERWOOD, B. J. EKSTR AND. B. R., \& KEPPEL. G. An analysis of intralist similarity in verbal learning with experiments on conceptual similarity. Journal of Verbal Learning \& Verbal Behavior, 1965, 4, 447-462.

UNDER WOOD, B. J, \& SCHULZ, R. W. Studies of distributed practice: $X X I$. Effect of interference from language habits. Journal of Experimental Psychology, 1961,62,571-575. 